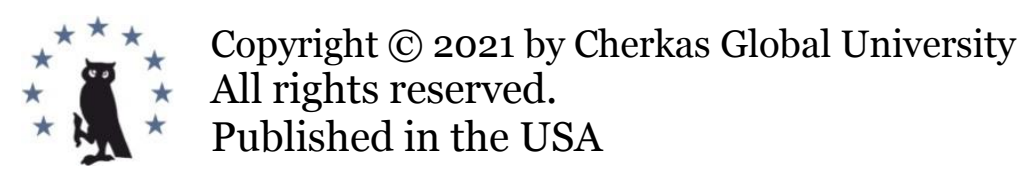

European Journal of Contemporary Education

E-ISSN 2305-6746

2021. 10(4): 958-968

DOI: $10.13187 /$ ejced.2021.4.958

https://ejce.cherkasgu.press

IMPORTANT NOTICE! Any copying, reproduction, distribution, republication (in whole or in part), or otherwise commercial use of this work in violation of the author(s) rights will be prosecuted in accordance with international law. The use of hyperlinks to the work will not be considered copyright infringement.

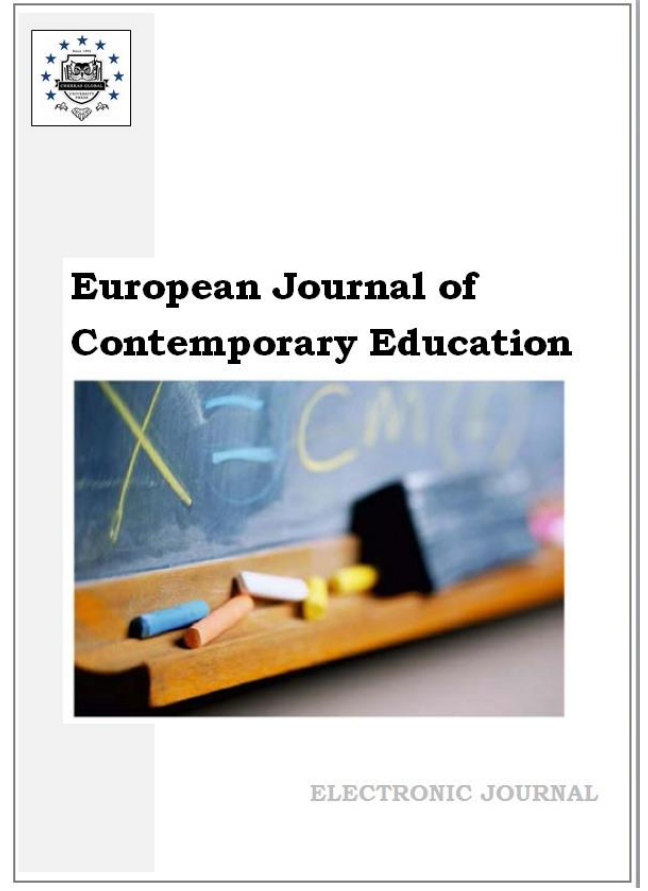

\title{
The Role of Scaffolding through Peer Collaborative Feedback in EFL Literature Students' Oral Presentation of Short Stories
}

Fatemeh Khonamri a, Mahsa Soleimani a, Hedviga Tkacova ${ }^{\text {b }{ }^{*} \text {, Zita Jenisová c }}$

a University of Mazandaran, Mazandaran Province, Babolsar, Iran

${ }^{b}$ Catholic University in Ruzomberok, Ruzomberok, Slovakia

c Constantine the Philosopher University in Nitra, Nitra, Slovakia

\begin{abstract}
The purpose of the present empirical research was to investigate the effects of peer assessment on students' oral presentation of short stories. With the attempt to investigate the effectiveness of peer feedback, a quantitative research study was conducted. The participants were selected randomly from groups of an 8-group class taking 'Oral Reproduction of Short Stories Course' at the University of Mazandaran. Students' interactions were recorded fully in research groups so that the transcription could be used for the analysis of the data. To be able to decide whether there were any changes in student' oral performance after the treatment, they participated in a pretest at the beginning of the term and a posttest at the end of the term and the results were subjected to paired sample T-test analysis in order to investigate the changes, if any. By analyzing the data, it was observed that the students were mainly concerned with giving feedback on gestures, eye contact, tone of voice and sometimes pronunciation. Grammatical and lexical errors seemed to be fewer than other types by peers. However, an analysis of their written feedback in the form of a checklist showed that they did think there were some inadequacies but refused to say so orally. In the comparison of the pre and posttest results, significant changes were observed after the treatment, and the $\mathrm{P}$ value was ( $\operatorname{sig}=0.03$ ) which meant that there was a significant difference between students' pre- and posttest performance.
\end{abstract}

Keywords: corrective feedback, peer assessment, socio-cultural approach, oral performance, EFL Literature.

\footnotetext{
* Corresponding author

E-mail addresses: hedwiga.tkacova@mail.com (H. Tkáčová), fkhonamri@umz.ac.ir (F. Khonamri), m.soleimani_1991@yahoo.com (M.Soleimani), zjenisova@ukf.sk (Z. Jenisová)
} 


\section{Introduction}

In educational research, there have been numerous studies on peer feedback processes of learners (McConlogue, 2015). Peer feedback means that 'learners work together and comment on one another's work or performance and provide feedback on strengths, weaknesses and suggestions for improvement' ( $\mathrm{Yu}, \mathrm{Hu}, 2017$ : 178). Meanwhile, Carless and Boud (2018) defined feedback as "a process through which learners make sense of information from various sources and use it to enhance their work or learning strategies" (p. 1315). In peer assessment, there are many different sources of information which include assessment criteria, received feedback, interaction with classmates, and coaching from the teacher. Carless and Boud (2018) have also developed the notion of student feedback literacy. It means that learners who are feedback literate will have a better understanding of the purpose of their assessments and assume an important role for peer feedback.

Despite the potential value in incorporating peer feedback in EFL classes, this phenomenon is still green in the EFL context (Peng, 2010), and the idea of manipulating this phenomenon in classroom contexts has not fully improved yet. From the cognitive aspect, language awareness helps attention and noticing which facilitate learning by helping learners to get the accurate formmeaning mapping (Svalberg, 2007). This goal seems to be accomplished by providing corrective feedback during meaningful interaction. There has been increasing amount of attention given in higher education to the concept of peer assessment or peer feedback which can be understood as educational arrangement in which students assess the quality of their fellow students' work and provide each other with feedback. This development is in line with other recent developments in university teaching such as collaborative learning and writing, and real-life task performance (Berg et al., 2006; Paul et al., 2017; Gadušová, Hašková, 2015; Azizi et al., 2021; Hašková et al., 2020; Pushkarev, Pushkareva, 2019; Simel Pranjić, 2021).

Peer collaboration has also been investigated largely in the literature with a focus on the effectiveness of peer scaffolding. However, the bulk of research on peer scaffolding is in the area of L2 writing within ESL contexts (De Guerrero, Villamil, 2000; Storch, 2002; Storch, 2005; Storch, 2007; Shehadeh, 2011). Peer scaffolding seems to be overlooked in L2 oral and speaking skills. Additionally, most research on L2 scaffolding focuses on ESL rather than EFL setting (De Guerrero, Villamil, 2000; Storch, 2002; Storch, 2005; Storch,2007). This shows that even though a good number of studies have investigated the effects of learner-teacher interaction, the phenomenon of peer interaction is still green in EFL contexts. Therefore, exploring the role of peer feedback in improving EFL students' oral performance would shed light on how teachers and learners can benefit from peer support in developing learners' English speaking ability. According to socio-cultural perspective, language related episodes could operationalize language awareness. Language related episodes are defined as "any part of the dialogue in which students talk about the language they are producing, question their language use, or other- or self-correct" (Swain, 1988; Stranovská et al., 2016; Stranovská et al., 2019).

According to Donato (1994) learners' shift of attention to formal aspects of language is discussed within interaction in which two people scaffold knowledge. The studies show that the students are capable of working cooperatively in order to communicate breakdowns and coconstruct knowledge (Donato, 1994; Ohta, 2000). However, the degree to which the students can be educated to do so more efficiently has not been studied yet. The present study puts one step forwards and attempts to study peer interaction as a crucial learning opportunity by allowing students to provide peer feedback to each other in "oral reproduction of short stories" course and investigate if peer feedback can enhance learner accuracy and fluency.

Due to the positive nature of corrective feedback and specifically peer feedback, this study aims at attaining these objectives:

1. Creating a communicative environment among learners;

2. Raising language accuracy and fluency and finally;

3. Enhancing language awareness.

The framework of this study is socio-cultural theory which was proposed by Vygotsky. Within this perspective, error correction is regarded as a social activity which involves joint participation and meaningful transactions between the learner and the teacher. The main theme of Vygotskian socio-cultural perspective is that knowledge is social in nature and is constructed through the process of collaboration, interaction and communications among learners in social settings (Vygotsky, 1987; Vosoughi, 2014). Socio-cultural theory emphasizes the social nature of learning. 
Learners interact with the "expert" adult teacher in the context of social interaction leading to understanding (Rohler, Cantlon, 1996; Kazemi, 2012). Vygotsky, in socio-cultural theory emphasizes that mind is mediated. He states that human beings make use of different symbolic tools for two reasons: 1. To interpret, and 2. to regulate the world they live in. Language as Vygotsky believes is one of those symbolic tools. We can both interpret and regulate others by language. Thus, this interpreting and regulating others has to be achieved by means of a tool; and the most important tool as Vygotsky believes is language (Vygotsky, 1987). Therefore, mediation means that our relationship with the world around us is indirect. Tkáčová and Slivka shows indirect relationship between people and the world when they remind Plato's parables, and point on the using of social media that are, "one of the most suitable tools for emerging from "the cave parables" to open minds" (Tkáčová, Slivka, 2021). Similarly, Pavlíková points an example of indirect relationship with the world seen on contemporary American writer Don DeLillo, who's characters find expression for example through the technologies they "fetishize" (Pavlíková, 2018; Pavlíková, 2019: 43-57).

Language under Vygotskyan theory is "a means for engaging in social and cognitive activity" (Ahmed, 1994: 149). According to Vygotsky, knowledge is the transition from inter-mental (between individuals) to intra-mental (within an individual). In other terms, according to Vygotsky, mental functions of the mind are primarily social and mutual and emerge inside afterwards (Vygotsky, 1987).

A fundamental principle of Vygotskian framework is the notion of Zone of Proximal Development (ZPD). According to socio-cultural perspective, learning results in interaction inside ZPD. Vygotsky defined ZPD as "the distance between the actual development level as determined by independent problem solving and the level of potential development as determined through problem solving under adult guidance or in collaboration with more capable peers" (Vygotsky, 1987: 54). Vygotsky believes that instruction should take place within ZPD in order to cause progress (Vygotsky, 1987).

The notion of scaffolding is relevant to this research, too. Donato defined this concept as "a situation where a knowledgeable participant can create supportive conditions in which the novice can participate, and extent his or her current skills and knowledge to higher levels of competence" (Donato, 1994: 40). It means that learners require to be supported by their peer or teachers in order to gain progress. Aljaafreh and Lantolf's study revealed that every type of corrective feedback was effective if it was negotiated between the learner and the teacher and was offered at the right point or within the learner's zone of proximal development. So according to their study, scaffolding which leads to language development, should occur within zone of proximal development (Aljaafreh, Lantolf, 1994).

Over the past decade, an increasing number of studies have been conducted within EFL students (Amurskaya et al., 2017; Pulverness et al., 2017; Irwansyah et al., 2019; Azizi et al., 2020; Stranovská, Gadušová, 2020; Gadušová et al., 2021; Kamenická, 2021) because current constant influx of new knowledge accompanied by increasing volumes of information lead to the need to improve skills and develop the capacities of individuals (Martino, 2020; Sirotová, Michvocíková, 2021).

There has been also bulk of studies relevant to providing guided assistance by teachers (Ulichny, 1991; Soradova et al., 2018; Vasbieva et al., 2018; Kalugina, Tarasevich, 2018; Birova, Kralova, 2018; Gadušová et al., 2019; Gadušová et al., 2020; Azizi et al., 2020; Pupikova et al., 2020; Dvoryatkina et al., 2021) to reduce stress in class for teachers and students alike (Azizi, Králik, 2020), to keep teachers and students active (Pavlíková et al., 2021), to make the formation of sustainable development competencies (Levchyk et al., 2021) or educational priorities (Kobylarek et al., 2021; Tvrdoň, 2020), to improving motivation (Cobo et al., 2020; Grajcevci, Shala, 2021) as well as cognitive resources of the individual (Rubacha et al., 2016), to improving satisfaction (Albelbisi et al., 2021; Tvrdon et al., 2021), the foreign language proficiency levels (Novikova et al., 2020) and literacy of students in the context of their professional development in the university (Maksaev, et al., 2020), while in this research, the main focus is to discover how learners could benefit from peer scaffolding during oral presentation.

The purpose of the present research study was twofold; first it investigated whether peer corrective feedback practices were able to improve learners' accuracy during an oral presentation; and second to focus on the nature of group dynamics with regard to the type of the feedback they gave and any possible changes that they might have gone through in this regard. 
Thus, the present study seeks to answer the following research questions:

1. Does peer feedback affect students' oral language accuracy?

2. What type of feedback is most commonly provided by peers in their friend's oral performance?

\section{Methodology}

The conducted study was classroom-centered research which had the purpose of investigating peer interactions, mainly learner-learner interactions in the form of feedback. Peer interactions were inspected in order to see what really happens during peer interactions and with the objective to evaluate this phenomenon as a means to increase or decrease learning opportunities. The focus of this study was to observe learners' main attention of giving feedback according to the checklist they were given at the beginning of the term. And then to record and transcribe the data which was observed and analyzed.

It should be mentioned that this study used a quantitative research design for the analysis of the results followed by a qualitative analysis of students' views.

For the purpose of examining whether this type of feedback through interaction would improve students' oral skills in term of accuracy, a quantitative analysis deemed necessary. Thus, through pre-test-treatment-posttest quasi-experimental design, the study attempted to discover the effect of peer feedback as a supposedly useful method on students' oral efficiency.

\section{Participants}

The participants of this study were junior students taking "Oral Reproduction of Short Stories" course at the University of Mazandaran. They were 32 female students who made four collaborative groups each consisting of 8 members. All of them were aged from 18 to 20 and had mixed level of proficiency.

\section{Data collection and analysis}

At the beginning of the term, the participants (the members of the collaborative group) took part in a pretest. Three different storyboards were copied and spread among the participants and they were asked to choose one of those copies and were given a few minutes time in order to reflect upon the storyboard and build their own story based on that. Then, each of them was asked to present the story individually while their presentation was being audio-taped. In order to encourage the students to genuinely participate in the study, the advantages of using peer feedback were explained to them. As the term started, a checklist which was a single paper and contained different aspects of a good oral presentation was distributed and explained to the whole class. Then the expectations of the course and the instructor were fully explained to the participants. They were told to select a short story suitable for presentation on the basis of the guidelines given to them in the first session. Then the whole class was divided into several groups. Each member of the group had to prepare a summary of the short story at home and practice it as well. Then, each session, one student should present his or her short story while other students were listening and taking notes of the points of strength and weaknesses they observed.

After the presentation was over, the members of the collaborative group would provide the presenter with sufficient peer feedback on different kinds of errors, such as lexical and syntactic errors, and the parts of the presentation in which the presenter acted poorly such as poor eye contact and inappropriate gestures like excessive movements of hands and so on. The members of the collaborative group would audiotape the whole process, and would prepare a report for the instructor in which they wrote down every member's comment and suggestion for improving their friend's performance. After receiving feedback from the group members, the presenters of each group would go to another group named evaluative group and would present their revised stories based on the comments to a new group of listeners. They would receive feedback in the evaluative group as well and the presentation and the feedback process would be recorded in this group again. This was done for the purpose of making a comparison between the group dynamics and types of feedback. At the end of the term, the same students took part in the posttest. For the posttest, the students were given the same story boards as the pretest and each student was given a few minutes time to prepare the story which they had made once for the pretest. The data was audiotaped as well.

Based on the theoretical framework, this study assumes that learning happens in participation, and without having participation it does not take place. Aroused by the socio-cultural theory, this study follows the views that conversation is essential for learning and through 
conversation one can have better understanding of new concepts. The central concept of sociocultural theory is that human beings' development is strengthened by language. If we want to improve in our daily lives, we have to talk about it beforehand. Often, through a dialogue with, possibly, a more experienced professional, we are scaffolded or assisted in making sense and acquiring deeper insights of complex phenomena. Through talk, new realizations and grater insights come about and get their first airing. Dialogue can establish proximal processes or contexts that create opportunities for learning potential (Walsh, 2011).

In order to examine the effects of peer feedback on students' oral performance, the peer interactions of four groups were analyzed. And the types of peer feedback which were provided during the interactions were spotted.

\section{Results}

The first part of the analysis deals with the students' pre- and posttest and the effect of peer feedback on the accuracy at the beginning and the end of the term are compared. In the second part, the types of corrective feedback provided by the collaborative group are discussed.

\section{Research Question 1: Does peer feedback affect students' oral accuracy?}

In order to examine the influence of peer feedback on students' accuracy, a pre- and posttest were conducted. In both of them, the students were given three series of story boards to choose from. As the pre-test they were given enough time to think about the story and build it, and then present it individually. The same storyboards were given to the same students in order to present as the posttest. At the outset, a test of normality was run the result of which is illustrated below in Table 1.

Table 1. Tests of Normality

\begin{tabular}{|l|l|l|l|l|l|l|}
\hline \multicolumn{3}{|c|}{ Kolmogorov-Smirnova } & \multicolumn{3}{c|}{ Shapiro-Wilk } \\
\hline & Statistic & Df & Sig. & $\begin{array}{l}\text { Statist } \\
\text { ic }\end{array}$ & Df & Sig. \\
\hline $\begin{array}{l}\text { PRET } \\
\text { EST }\end{array}$ & .264 & 31 &. & .866 & 31 & .281 \\
\hline
\end{tabular}

The reason of conducting tests of normality was to see if the participants had normal distribution of knowledge in the beginning, and no significant difference was observed (sig = 0.281) in the students' performance. Thus, the results of the research could be related to the current treatment.

For answering the first research question, the error free T-unit analysis was used in order to measure the accuracy of the students' performance in both pre- and posttest. The formula of T-unit analysis is presented below:

$$
\frac{\text { error free clauses }}{\text { total clauses }} \times 100
$$

Fig. 1. The formula of T-unit analysis

Table 2. Descriptive Statistics of Pre-test and Post-test

\begin{tabular}{llllll}
\hline & Group & $\mathrm{N}$ & Mean & Std. Deviation & Std. Error Mean \\
\hline \multirow{2}{*}{ Group } & Pre-test & 32 & 16.2 & .451 & .81 \\
& Post-test & 32 & 21.3 & .654 & 1.008 \\
\hline
\end{tabular}


Table 3 shows the results of the paired samples t-test carried out on the learners' scores for pre-test and post-test. The data of Levene's test for equality of variances reveals that it does not violate the assumption of equal variance as the sig value in Levene's test is greater than .05 $(\mathrm{t}(29)=$ $.65, \alpha=.05, p=.03)$.

As Table 3 indicates, the sig value (2-tailed) is .03 which is smaller than the required cut-off of .05. Therefore, it can be said that there is a statistically significant difference between the participants' performance in pre-test and post-test and their performance in post-test was better than the pretest. This shows that peer collaborative feedback was effective.

Table 3. Paired Samples T-test for Pre-test and Post-tes

\begin{tabular}{|c|c|c|c|c|c|c|c|c|}
\hline & $\begin{array}{l}\text { Leve } \\
\text { Test } \\
\text { Equa } \\
\text { of } \\
\text { Vari }\end{array}$ & $\begin{array}{l}\text { ne's t-te } \\
\text { for } \\
\text { lity } \\
\text { inces }\end{array}$ & est fo & r Equa & lity of $M$ & Ieans & & \\
\hline & $\mathrm{F}$ & Sig. $t$ & Df & $\begin{array}{l}\text { Sig. } \\
(2-\end{array}$ & $\begin{array}{l}\text { Mean } \\
\text { Differe }\end{array}$ & $\begin{array}{l}\text { Std. } \\
\text { Error }\end{array}$ & $\begin{array}{l}95 \% \\
\text { Confid }\end{array}$ & nce \\
\hline & & & & tailed) & & Differe & nInterva & of the \\
\hline & & & & & & ce & Differe & nce \\
\hline & & & & & & & Lower & Upper \\
\hline $\begin{array}{l}\text { Equal } \\
\text { variances } \\
\text { assumed }\end{array}$ & .579 & $\begin{array}{r}.4513 .6 \\
56\end{array}$ & 31 & .03 & .850 & 1.295 & -1.772 & 3.47 \\
\hline $\begin{array}{l}\text { Equal } \\
\text { variances } \\
\text { assumed }\end{array}$ & & $\begin{array}{l}3.6 \\
5\end{array}$ & & .02 & .850 & 1.295 & -1.776 & 3.47 \\
\hline
\end{tabular}

Research question 2: What type of feedback is mostly provided by peers in their friend's oral performance? After analyzing the transcripts of the groups' recorded interactions and coding them, feedback types were identified with the help of a second rater. Some of the most pertinent emerged categories are presented and described below in Table 5. The Table shows the frequency of occurrence of five emerged categories.

Table 5. The numbers of feedback

\begin{tabular}{|l|c|}
\hline Types of feedback & Numbers \\
\hline 1. Morpho-syntactic feedback & 6 \\
\hline 2. Grammatical feedback & 5 \\
\hline 3. Content feedback & 21 \\
\hline 4. Body language feedback & 6 \\
\hline $\begin{array}{l}\text { 5. Tone of voice, intonation and } \\
\text { pronunciation feedback }\end{array}$ & 7 \\
\hline
\end{tabular}

M-S FB= morpho-syntactic feedback

$\mathrm{G} \mathrm{FB}=$ grammatical feedback

$\mathrm{C} \mathrm{FB}=$ content feedback

$\mathrm{BL} \mathrm{FB}=$ body language feedback

$\mathrm{I}, \mathrm{T} \& \mathrm{P} \mathrm{FB}=$ intonation, tone of voice and pronunciation feedback

Analysis of the recordings indicated that in all the treatment sessions students engaged in providing different types of feedback with different proportion to their peers. And it seemed that 
the kinds of feedbacks provided did not undergo specific changes. As can be seen in the table, the most frequent feedback given was content feedback (21). This means that students' attention was more focused on meaning and the content that was delivered in oral interaction than form.

Most of peers' feedback revolved around the clarity of content and its organization. Both collaborative group members and evaluative groups were concerned with making sure that the content was sufficiently and satisfactorily presented. For example, the questions that they asked for clarifying their own misunderstanding showed how important grasp of content was to them. They often asked questions about the characters, events and sometimes the ending to make sure that the information presented was correct. In cases that peers had already read the story, the feedback became even more interesting in that they sometimes found fault with parts of the story that they thought were distorted or changed somehow. In such cases, peers gave advice on how to make amendments to the story to make it right. If this happened in the collaborative group, the presenter was lucky and could do a much better job in the evaluative group.

According to the table above, the least frequent feedback type was the grammatical feedback. This was an interesting finding since even though students were directed to attend to their peers' formal aspects of the language in the checklist, very few of such feedback was provided. This means that their preoccupation with the meaning and communication of the ideas seemed to have prevented them from attending to form in their friend's presentation. And the very few cases noticed were related to such issues as he/she confusion in the use of third person pronoun, and tense inconsistency mostly.

The other feedback types given by the peers (morpho-syntactic feedback, body language feedback, and intonation, tone of voice and pronunciation feedback) were also scarce in comparison to the content feedback. Peers made mention of the presenters' tone being monotonous, they told them about their lack of eye contact mostly, and sometimes they criticized the presenters for excessive hand movement during the presentation which they found distracting.

In sum, it should also be mentioned that, although all students had collaboration in the feedback process, some of the students had more dominant roles and took control of the group. Moreover, the types of feedback which were mostly provided were in line with the feedback they offered earlier, and this was seen in almost all sessions.

\section{Discussion}

This study attempted to find the effects of peer feedback on students' oral presentation of short stories during the "Oral Reproduction of Short Stories" course. The findings of the study were based on the observation of four groups of students' interactions in their own group which was termed as "collaborative group" and their presentation in other groups termed as "evaluative group", and also analyzing their pretest which was conducted at the beginning of the term and their posttest at the end of the term.

The results of this study are consistent with Skehan. He notes that there are two contrasting approaches to using group activities. The first, a structure-oriented approach, emphasizes form over meaning; the second, a communicatively oriented approach, focuses very little on form. Skehan argues in favor of an intermediate approach which strikes a balance between form and meaning by alternating attention between them (Skehan, 1998). This project clearly falls under the umbrella of the communicatively oriented approach and, as such, one of its primary weaknesses is an overemphasis on communication. This increases the risk that learners will become overly reliant on the use of communication strategies, because three aspects of speaking performance - accuracy, fluency, and complexity - compete with one another. Thus, the peer feedback task given to the learners in his project appears to have the greatest effect on speaking fluency and to a lesser degree, complexity; which is to some extent similar to the current study.

Moreover, he further argues that, because of the natural limitations in attention resources, this means that many learners will have limited cognitive capacity to attend to. Accuracy is a matter of no small concern since this situation can potentially lead to what Skehan called provoked fossilization the fossilization of incorrect lexicalized language which is acquired relatively early in the process of acquiring productive language skills. According to him, not only should sometime be reserved for focus on form, but ideally this should occur more than once in the project (Skehan, 1998). 
In comparison to previous studies in the realm of peer feedback such as Liang Hsu, which showed positive effects in some aspects of learning (Liang Hsu, 2012), the results of this study also showed any special changes in students' accuracy of English.

The peer feedback groups used throughout the research maximized group work and student talk time in class. This is in line with Butt-Bethlendy's study in which she gained similar results. One of the possibilities that she referred to in not achieving a complete positive result and which may be applicable to the present study as well is that it was perhaps due to the fact that this was the first time, they had encountered this method and therefore had limited understanding of the concept, or confidence in their own and their partners' abilities. She suggests that the most successful way of using the peer feedback seems to be a joint one given by both the students and the teacher (Butt-Bethlendy, 2013). This is also supported in other studies (Sato, Ballinger, 2012; Kavaliauskiene, Anusiene, 2012)

The results were also similar to Hoa Nguyen's study in which he investigated the ways Vietnamese English as a foreign language (EFL) students provided peer scaffolding to each other during a collaborative presentation task and how they benefited from this experience. This study too, demonstrated that collaborative group work created learning conditions where peers provided mutual help (Nguyen, 2013).

\section{Conclusion}

In this research, it was observed that peer feedback does lead to progress in language accuracy in the short term. Moreover, the results of a study by Pushkarev and Pushkareva who examined the characteristics of lifelong education within global cultural environment emphasized that the essential purpose of lifelong education should encompass training. Thus, teachers are required to raise students' awareness as well as provide them with the necessary training they need to ensure high quality education (Pushkarev, Pushkareva, 2016; Pushkarev, Pushkareva, 2018). This is especially important in contexts where the teacher intends to rely on peer collaboration and scaffolding to enhance language ability.

\section{Acknowledgements}

This work was supported by the Cultural and Educational Grant Agency (KEGA) of the Ministry of Education, Science, Research and Sports of the Slovak Republic based on project number $029 \mathrm{UKF} 4 / 2020$.

\section{References}

Ahmed, 1994 - Ahmed, M.K. (1994). Speaking as cognitive regulation: A Vygotskien prespective on dialogic communication, 146-158. In J. P. Lantolf (ed.) Vygotskian Approaches Second Language Research. Norwood, NJ: Ablex.

Albelbisi et al., 2021 - Albelbisi, N.A., Al-Adwan, A.S., Habibi, A. (2021). Self-regulated learning and satisfaction: A key determinants of MOOC success. Education and Information Technologies. 26(3): 3459-3481.

Aljaafreh, Lantolf, 1994 - Aljaafreh, A., Lantolf, J. (1994). Negative feedback as regulation and second language learning in the zone of proximal development. The Modern Language Journal. 78(4): 465-483.

Amurskaya et al., 2017 - Amurskaya, O.Y., Gimaletdinova, G.K., Khalitova, L.K. (2017). Multimedia Sanako study 1200 for TEFL in institution of higher education. XLinguae. 10(3): 229-236.

Azizi et al., 2020 - Azizi, M., Pavlíková, M., Masalimova, A. (2020). Exploring Literature Reading Classes in Terms of Types of Feedback Provided by EFL Teachers: Does Teaching Experience Play a Determining Role? Education and Self Development. 15(3): 19-36.

Azizi et al., 2021 - Azizi, M., Pavlíková, M., Slobodová Novaková, K., Baghana, J. (2021).

The Differential Effects of Dynamic Assessment Versus Coded Focused Feedback on the Process Writing of EFL Learners. European Journal of Contemporary Education. 10(2): 273-284.

Azizi, Králik, 2020 - Azizi, M., Králik, R. (2020). Incorporating Mindfulness into EFL Literature Courses to Foster Critical Reading Ability. Education and Self Development. 15(4): 21-31.

Berg et al., 2006 - Berg, I., Admiraal, W., Pilot, A. (2006). Design Principles and Outcomes of Peer Assessment in Higher Education. Studies in Higher Education. 31(3): 341-356. 
Birova, Kralova, 2018 - Birova, J., Kralova, Z. (2018). A tool called communicative curve applied for evaluation of similarities and differences between foreign language textbooks. European Journal of Contemporary Education. 7(1): 39-50.

Butt-Bethlendy, 2013 - Butt-Bethlendy, K. (2013). Developing fluency, accuracy and complexity in oral production through corrective peer feedback. Ablex: Sheffield Hallam University.

Carless, Boud, 2018 - Carless, D., Boud, D. (2018). The development of student feedback literacy: enabling uptake of feedback. Assessment \& Evaluation in Higher Education. 43(8): 1315-1325.

Cobo et al., 2020 - Cobo, M.O., Králik, R., Bianco, R. (2020). Refugees' L2 learning: new perspectives on language motivation research. XLinguae. 13(4): 64-80.

Donato, 1994 - Donato, R. (1994). Collective scaffolding in second language learning. In J.P. Lantolf and G. Appel (ed.) Vygotskian approaches to second language research (pp. 33-56). Norwood, NJ: Ablex.

Dvoryatkina et al., 2021 - Dvoryatkina, S.N., Shcherbatykh, S.V., Lopukhin, A.M. (2021). Scientific and methodological support for teachers in the context of gamification in mathematics study in the Russian system of additional education. RUDN Journal of Psychology and Pedagogics. 18(1): 140-152.

Gadušová, Hašková, 2015 - Gadušová, Z., Hašková, A. (2015). Training Educational Staff: Vision and Reality in Pre-service and In-service Training, pp. 2046-2053. In Edulearn 15 Proceedings. Barcelona, Spain: IATED Academy.

Gadušová et al., 2019 - Gadušová, Z., Hašková, A., Predanocyová, L. (2019). Teachers' professional competence and their evaluation. Education and Self Development. 14(3), 17-24.

Gadušová et al., 2020 - Gadušová, Z., Hašková, A., Szarszoi, D. (2020). Teachers' competences evaluation: Case study. Science for Education Today. 10(3): 164-177.

Gadušová et al., 2021 - Gadušová, Z., Pavlíková, M., Havettová, R. (2021). Intervention in teaching reading in a foreign language: development of divergent thinking and ambiguity tolerance. Journal of Education Culture and Society. 12(1): 297-313.

Grajcevci, Shala, 2021 - Grajcevci, A., Shala, A. (2021). Exploring achievement goals tendencies in students: the link between achievement goals and types of motivation. Journal of Education Culture and Society. 12(1): 265-282.

Hašková et al., 2020 - Hašková, A., Safranko, C., Pavlíková, M., Petrikovičová, L. (2020). Application of online teaching tools and aids during corona pandemics. Ad Alta - Journal of Interdisciplinary Research. 10(2): 106-112.

Irwansyah et al., 2019 - Irwansyah, D., Nurgiyantoro, B., \& Sugirin. (2019). Literature-Based reading material for EFL students: a case of Indonesian Islamic University. XLinguae. 13(3): 22-44.

Kalugina, Tarasevich, 2018 - Kalugina, O.A., Tarasevich, N.A. (2018). Smart technology integration into EFL teaching at the non-linguistic higher school. XLinguae. 11(1XL): 8-18.

Kamenická, 2021 - Kamenicka, J. (2021). Apple Tree Model of Emotion-Involved Processing: Videos for Emotions and Foreign Language Learning. Educational priorities in a post pandemic world. Journal of Education Culture and Society. 12(1): 103-116.

Kavaliauskiene, Anusiene, 2014 - Kavaliauskiene, G., Anusiene, L. (2014). Computerised Self-Evaluation of Performance in Professional English. Socialinés Technologios Social Technologies. 4(1): 25-36.

Kazemi, 2013 - Kazemi, S. (2013). A conversation analysis of English language teachers' elicitation repertoire to check learners' non/misunderstandings. Unpublished Thesis at the University of Mazandaran.

Kobylarek et al., 2021 - Kobylarek, A., Plavčan, P., Golestani, T.A. (2021). Educational priorities in a post pandemic world. Journal of Education Culture and Society. 12(2): 5-11.

Levchyk et al., 2021 - Levchyk, I., Chaikovska, H., Yankovych, O., Kuzma, I., RozhkoPavlyshyn, T. (2021). Formation of sustainable development competencies in primary school children. Journal of Education Culture and Society. 12(2): 341-360.

Liang Hsu, 2012 - Liang Hsu, Y. (2012). Implementing peer evaluation to improve students' participation in oral presentations in a large mechanical design class. Global Journal of Engineering Education. 14(3): 219-224.

Maksaev et al., 2020 - Maksaev, A.A., Vasbieva, D.G., Sherbakova, O.Y., Mirzoeva, F.R., Králik, $R$. (2020). Education at a Cooperative University in the Digital Economy. Studies in Systems, Decision and Control. 316: 33-42. 
Martino et al., 2021 - De Martino, M., Gushchina, Y. S., Boyko, Z. V., Magnanini, A., Sandor, I., Guerrero Perez, B. A., Isidori, E. (2021). Self-organisation in lifelong learning: Theory, practice and implementation experience involving social networks and a remote format. RUDN Journal of Psychology and Pedagogics. 17(3): 373-389.

McConlogue, 2015 - McConlogue, T. (2015). Making judgements: investigating the process of composing and receiving peer feedback. Studies in Higher Education. 40(9): 1495-1506.

Nguyen, 2013 - Nguyen, H.T.M. (2013). The EFL Context in Vietnam and East Asia. In Models of Mentoring in Language Teacher Education. English Language Education. Springer, Cham.

Novikova et al., 2020 - Novikova, I.A., Berisha, N.S., Novikov, A.L., Shlyakhta, D.A. (2020). Personality traits and foreign language proficiency in Russian linguistics and non-linguistics students. RUDN Journal of Psychology and Pedagogics. 17(3): 426-439.

Ohta, 2000 - Ohta, A. (2000). Rethinking recasts: A learner-centered examination of corrective feedback in the Japanese classroom, p. 47-71. J. Hall, J. \& L. Verplaeste (ed.) The construction of second and foreign language learning through classroom interaction. Mahwah, NJ: Erlbaum.

Paul et al., 2017 - Paul, A., Retnowati, E., Sweller, J. (2017). Can collaborative learning improve the effectiveness of worked examples in learning mathematics? Journal of Educational Psychology. 109(5), 666-679.

Pavlíková, 2018 - Pavlíková, M. (2018). The power of modern technologies in the fiction of Don DeLillo Communications. Scientific Letters of the University of Zilina. 20(1A): 57-60.

Pavlíková, 2019 - Pavlíková, M. (2019). Existential features of Soren Kierkegaard in modern American literature. Toronto: Kierkegaard Circle. Trinity College. University of Toronto.

Pavlíková et al., 2021 - Pavlíková, M., Sirotkin, A., Králik, R., Petrikovičová, L., Martin, J.G. (2021). How to Keep University Active during COVID-19 Pandemic: Experience from Slovakia. Sustainability. 13: 10350.

Peng, 2010 - Peng, J. (2010). Peer Assessment in an EFL Context: Attitudes and Correlations, 89-107. In M. T. Prior et al. (ed.) Selected Proceedings of the 2008 Second Language Research Forum: Exploring SLA Perspectives, Positions, and Practices. Somerville, MA: Cascadilla Proceedings Project.

Pulverness et al., 2017 - Pulverness, A., Klimova, I.I., Kalugina, O.A., Vasbieva, D.G., Ismagilova, L.R. (2017). The formation of students' intercultural communicative competence in an English language learning environment at a non-linguistic higher school. XLinguae. 10(4): 381-397.

Pupikova et al., 2020 - Pupikova, E., Kollarova, D., Birova, J. (2020). Career growth of teacher of pre-primary education through self-reflection in qualification thesis. Science for Education Today. 10(1): 174-190.

Pushkarev, Pushkareva, 2016 - Pushkarev, Y.V., Pushkareva, E.A. (2016). Continuous education philosophy in the context of global culture development. Novosibirsk State Pedagogical University Bulletin. 6(3): 60-67.

Pushkarev, Pushkareva, 2018 - Pushkarev, Y.V., Pushkareva, E.A. (2018). Human rights as a value of personal development in the knowledge society. Novosibirsk State Pedagogical University Bulletin. 8(3): 80-91.

Pushkarev, Pushkareva, 2019 - Pushkarev, Y.V., Pushkareva, E.A. (2019). Reflexive principles of personal development in the changing information content. Science for Education Today. 9(2): 52-66.

Rezaee, Mozaffari, 2011 - Rezaee, S., Mozaffari, F. (2011). Corrective feedback in SLA: classroom practice and future directions. International Journal of English Linguistics. 1(1): 19-31.

Rohler, Cantlon, 1996 - Rohler, L.R., Cantlon, D.J. (1996). Scaffolding: A powerfull tool in social constructivist classroom. [Electronic resource]. URL: http:/ebed3:Educ.Msu.Edu./Literacy/ papers/paperlr2.html

Rubacha et al., 2016 - Rubacha, K., Sirotová, M., Chomczyńska-Rubacha, M. (2016). Educational self-efficacy in teachers of various ethical orientations. The Slovak research. New Educational Review. 43(1): 193-200.

Sato, Ballinger, 2012 - Sato, M., Ballinger, S. (2012). Raising language awareness in peer interaction: a cross-context, cross-methodology examination. Language Awareness. 21(1-2): 157-179.

Shehadeh, 2011 - Shehadeh, A. (2011). Effects and student perceptions of collaborative writing in L2. Journal of Second Language Writing. 20(4): 286-305. 
Simel Pranjić, 2021 - Simel Pranjić, S. (2021). Development of a caring teacher-student relationship in higher education. Journal of Education Culture and Society. 12(1): 151-163.

Sirotová, Michvocíková, 2021 - Sirotová, M., Michvocíková, V. (2021). Virtual Reality - Part of Supervised Teaching Practice for University Students - Future Teachers? European Journal of Contemporary Education. 10(1): 127-136.

Skehan, 1998 - Skehan, P. (1998). A Cognitive Approach Language Learning. Oxford: Oxford University Press.

Soradova et al., 2018 - Soradova, D., Kralova, Z., Birova, J. (2018). "Phonics generalizations" in teaching foreign language pronunciation. Novosibirsk State Pedagogical University Bulletin. 8(4): 46-54.

Storch, 2002 - Storch, N. (2002). Patterns of interaction in L2 pair work. Language Learning. 52(1): 119-158.

Storch, 2005 - Storch, N. (2005). Collaborative writing: Product, process, and students' reflections. Journal of Second Language Writing. 14(3): 153-173.

Storch, 2007 - Storch, N. (2007). Investigating the merits of pair work on a text editing task in ESL classes. Language Teaching Research. 11(2): 143-159.

Stranovská et al., 2016 - Stranovská, E., Hvozdiková, S., Munková, D., Gadušová, Z. (2016). Foreign Language Education and Dynamics of Foreign Language Competence. The European Journal of Social and Behavioural Sciences. 17(3): 2141-2153.

Stranovská, Gadušová, 2020 - Stranovská, E., Gadušová, Z. (2020). Learners' Success and Self-esteem in Foreign language. Reading Comprehension, Education and Self Development. 15(3): 109-119.

Stranovská et al., 2019 - Stranovská, E., Gadušová, Z., Ficzere, A. (2019). Factors Influencing Development of Reading Literacy in Mother Tongue and Foreign Language, 69016907. ICERI 2019: Conference proceedings: 12th International conference of education, research and innovation.

Svalberg, 2007 - Svalberg, A. (2007). Language awareness and language learning. Language Teaching. 40(4): 287-308.

Swain, 1998 - Swain, M. (1998). Focus on form through conscious reflection, 64-81.

In C. Doughty \& J. Williams (ed.) Focus on form in classroom second language acquisition. Cambridge: Cambridge University Press.

Tvrdoň, 2020 - Tvrdoň, $M$. (2020). Equal opportunities - comparison of ethical education and religious education curricula, pp. 5517-5523. In Inted2017: 11th International technology, education and development conference, Valencia, Spain: IATED Academy.

Tvrdoň et al., 2021 - Turdoň, M., Kondrla, P., Mesarosova, L. (2021). Social work as a tool for anomie correction on second stage of primary school. AD ALTA-Journal of Interdisciplinary Research. 11: 353-357.

Ulichny, 1991 - Ulichny, P. (1991). The English High School / Harward Collaboration Project: Year Two Report. Interim Report to the Development of Education. Washington (DC): Secretary's Fund for Innovation in Education.

Vasbieva et al., 2018 - Vasbieva, D.G., Sokolova, N.L., Masalimova, A.R., Shinkaruk, V.M., Kiva-Khamzina, Y. L. (2018). Exploring the EFL teacher's role in a smart learning environment a review study. XLinguae. 11(2): 265-274.

Villamil, De Guerrero, (n. d.) - Villamil, O.S., De Guerrero, C.M. (n. d.) Sociocultural Theory: A framework for understanding social-cognitive dimensions of peer-feedback, 23-39. K. Hyland, K. \& F. Hyland. Feedback in Second Language Writing. Cambridge: Cambridge University Press.

Vosoughi, 2014 - Vosoughi, M. (2014). Raising Language Awareness and Reciprocal Learning through Peer Corrective Feedback. University of Mazandaran.

Vygotsky, 1987 - Vygotsky, L.S. (1987). Mind in society: The development of higher psychological processes. Cambridge, MA: Harward University Press.

Walsh, 2011 - Walsh, S. (2011). Exploring classroom discourse language in action. London: Routledge.

$\mathrm{Yu}, \mathrm{Hu}, 2017-\mathrm{Yu}, \mathrm{S} ., \mathrm{Hu}$, G. (2017). Understanding university students' peer feedback practices in EFL writing: Insights from a case study. Assessing Writing. 33: 25-35. 